\title{
Application of Protek Duo RD Dual Lumen Cannula Without Anticoagulation Use in Patients Successfully Bridged to Lung Transplantation
}

\author{
Michael Markovich ${ }^{1}$, Jessia Harris ${ }^{1}$, Sanna Mohammad ${ }^{1}$, April Grant MD ${ }^{2}$, Vicente Orozco \\ Sevilla ${ }^{2}$, Rodrigo Vianna MD, $\mathrm{PhD}^{3}$, Matthias Loebe ${ }^{1}$, and Ali Ghodsizad ${ }^{4}$ \\ ${ }^{1}$ Jackson Memorial Hospital \\ ${ }^{2}$ Affiliation not available \\ ${ }^{3}$ University of Miami Miller School of Medicine \\ ${ }^{4}$ University of Miami
}

June 4, 2020

\begin{abstract}
Respiratory failure is a common cause of death. It is proven that Extracorporeal Membrane Oxygenation (ECMO) cannulation is successful in bridging patients to lung transplantation. Here we report on a 51-year-old patient with COPD who was bridged successfully to lung transplantation using venous-venous ECMO with a Protek Duo RD dual lumen cannula; which contributed to our success in bridging to transplant without the need for anticoagulation. Here we confirm that the clinical application use of the cannula without IV Heparin use is safe and feasible.
\end{abstract}

\section{Introduction}

Extracorporeal membrane oxygenation (ECMO) can be used to support patients with end-stage heart and lung failure. Depending on the circuit, it includes a centrifugal pump, heat exchanger and oxygenator. The first adult ECMO case was reported in 1972. ${ }^{12}$ The use of Veno-venous ECMO (VV-ECMO) for a bridge to lung transplant has been increasing in the last decade. ${ }^{8}$ Risks associated with cannulation include bleeding, infection, and clotting. ${ }^{13}$ The goal of this review is to outline the outcome of ECMO application in a single patient, using the Protek Duo RD cannula without administrating IV Heparin to maintain anticoagulation management (heparin drip titrated to an activated partial thromboplastin time of 50 seconds). ${ }^{9}$

The Protek Duo RD is a dual lumen cannula which does not have a Carmeda AB coating. It includes two lumens. The inside lumen is connected to the tip of the cannula, which suctions the deoxygenated blood. The outside lumen brings the oxygenated blood to the right atrium.

\section{Case Report}

A 51-year-old female, diagnosed with $\mathrm{COPD}$ due to alpha-1 antitrypsin $\left(\mathrm{A}_{1} \mathrm{AT}\right)$ deficiency with a Lung Allocation Score (LAS) of 37 for double lung transplantation, presented to the emergency department with worsening shortness of breath while needing $8 \mathrm{~L} / \mathrm{min}$ of oxygen via nasal cannula at home. The patient had a past 40-pack year smoking history. No other significant medical or family history was noted. She underwent venous-venous (VV) ECMO cannulation using Protek Duo RD as an intended bridge to lung transplant due to worsening hypoxemic and hypercapnic respiratory failure. The patient underwent ultrasound-guided percutaneous ECMO cannulation with Protek Duo RD 31 Fr dual lumen cannula in the right internal jugular vein. Using the Seldinger technique and a TTE, the $31 \mathrm{Fr}$ venous cannula was inserted into the right 
internal jugular vein and advanced to the inferior vena cava (IVC) where the cannula was secured in place. She tolerated the procedure well and was extubated on high-flow nasal cannula post-ECMO transplantation day 2. Tracheostomy was performed following extubation. She was out of bed and ambulating post-ECMO cannulation day 2 following the ECMO implantation. During the first week post-ECMO transplantation, she started to have a bilateral spontaneous pulmonary hemorrhage. The transfusion of several FFPs, cryoprecipitates, as well as Factor 7, was needed to control the bleeding. The patient was sent to IR which performed coiling of intercostal arteries. Beginning with the bleeding, IV heparin was stopped. The pulmonary hemorrhage could be well controlled for the next five weeks. Six weeks after, she successfully underwent lung transplantation; she was decannulated POD 4. In the following days, she recovered well in our ICU and was discharged to rehab on POD 8.

\section{Discussion}

VV- ECMO is indicated in patients with severe respiratory failure that is refractory to optimal mechanical ventilation, medical therapy, patients with reversible respiratory failure including acute respiratory distress syndrome (ARDS) ${ }^{10}$ and as a bridge to lung transplantation. ${ }^{3}$ However, patients with irreversible failure and those who are not eligible to be bridged to lung transplants should not be placed on VV-ECMO cannulation. ${ }^{10}$ So, an exit strategy should be available before selecting the patient as a VV-EECMO candidate. Currently, there are four dual lumen cannula systems from different companies, including the Protek Duo/RD and Avalon Elite.

Considering the difference between the Protek Duo RD and the Avalon cannula, there have been concerns in not using any heparin in the clinical practice.

The Protek Duo RD has multiple inflow holes on the most distal portion of the cannula and several outflow holes on the central part of the cannula, which we assume permits for more laminar blood flow as opposed to turbulent flow seen in the Avalon Elite cannula, which has a single outflow port. Turbulent blood flow could be the cause of more hemolysis in the Avalon cannula. Laminar flow is more similar to normal physiological conditions and has a lower Reynolds number. The lower Reynolds number is directly proportional to velocity and will result in less shear stress on the vessels. Furthermore, adequate flow is produced; this allows for a high flow which will result in recirculation. Turbulent flow produces low flow which will result in reduced movement and low shear stress; which are major risk factors for thrombosis formation.

We assume that the circumferential holes in the Protek Duo RD allow a better laminar flow of the oxygenated blood in the cannula when comparing with the flow pattern in the Avalon cannula which has only one quadrangle outflow.

Furthermore, the positioning of the cannula is considerably easier in the instance of the Protek Duo RDcannula, as it permits circumferential delivery of oxygenated blood. In the case of the Avalon cannula, if the outflow is presenting away from the tricuspid valve, it requires meticulous repositioning. Hence, the Protek Duo RDcannula is easier to position without requiring more TEE or TTE guided positioning.

In this patient, the Protek Duo RD was conveniently and effectively used. It improved patient rehabilitation while minimizing blood loss and risk of thrombosis, and shortened procedure time while improving clinical outcomes in right ventricular failure. To our surprise, as we did not have any other clinical bailout; our patient tolerated very well being on VV-ECMO for several weeks without IV Heparin. Moreover, even with extensive application of pro-coagulation factors, including Factor 7, the patient did not clot off the ECMO circuit despite a routine oxygenated change during the pre-transplant hospital stay.

\section{References}

1. Jayaraman A, Cormican D, Shah P, Ramakrishna H. Cannulation Strategies in Adult Veno-arterial and Veno-venous Extracorporeal Membrane Oxygenation: Techniques, Limitations, and Special Considerations.Ann Card Anaesth. 2017 Jan; 20(Suppl 1): S11-S18. https://www.ncbi.nlm.nih.gov/pmc/articles/PMC5299823/ 
2. Pavlushkov E, Berman M, Valchanov K. Cannulation techniques for extracorporeal life support. Ann Transl Med. 2017 Feb; 5(4): 70. https://www.ncbi.nlm.nih.gov/pmc/articles/PMC5337209/

3. Brozzi N, Cifuentes R, Haq S, Ghodsizad A, Loebe M. Aorto-pulmonary bypass shunt for intraoperative right ventricular support during LVAD implantation. $J$ Card Surg. 2019; 1-3. https://doi.org/10.1111/jocs.14375

4. Brozi N, Beduschi T, Salerno T, Cifuentes R, Ghodsizad A, Martin E, Vianna R, Loebe M. Combined off-pump coronary bypass grafting without heparin and liver transplantation: A novel approach to a complex dilemma.

5. Thabut G, Dauriat G, Stern J, Logeart D, Levy A, Marrash-Chahla R, Mal H. Pulmonary Hemodynamics in Advanced COPD candidates for Lung Volume Reduction Surgery or Lung Transplantation. Chest. 2005; Vol 127, Issue 5, 1531-1536. https://www.sciencedirect.com/science/article/abs/pii/S0012369215347152

6. Gomez-Abraham J.A., Brann S, Aggarwal V, O'Neill B, Alvarez R, Hamad E, Toyoda Y. Use of Protek Duo Cannula (RVAD) for Percutaneous Support in Various Clincial Settings. A Safe and Effective Option. J Card Surg. 2018. https://www.jhltonline.org/article/s1053-2498(18)30243-2/pdf

7. James J. Hathcock. Flow Effects on Coagulation and Thrombosis.Arteriosclerosis, Thrombosis, and Vascular Biology.2006;26;1729-1737. https://www.ahajournals.org/doi/10.1161/01.ATV.0000229658.76797.30

8. Brasseur A, Scolletta S, Lorusso R, Raccone FS. Hyvrid extracorporeal membrane oxygenation. $J$ Thorac Dis. 2018;10(Suppl 5):S707-S715. https://www.ncbi.nlm.nih.gov/pmc/articles/PMC5911562/

9. Javidfar J, Brodie D, Wang D, Ibrahimiye A, Yang J, Zwischenberger J, Sonnet J, Bacchetta M. Use of Bicaval Dual-Lumen Catheter for Adult Venovenous Extracorporeal Membrane Oxygenation. Ann Thorac Surg. 2011;91:1763-9. https://www.annalsthoracicsurgery.org/article/S0003-4975(11)00543$1 / \mathrm{pdf}$

10. Banfi C, Pozzi M, Siegenthaler N, Brunner M, Tassaux D, Obadia J, Bendjelid K, Giraud R. Venovenous extracorporeal membrane oxygenation: cannulation techniques. J Thorac Dis. 2016; 8(12): 3762-3773. https://www.ncbi.nlm.nih.gov/pmc/articles/PMC5227239/

11. Kapur N, Esposito M, Bader Y, Morine K, Kiernan M, Pham D, Burkhoff D. Mechanical Circulatory Suport Devices for Acute Right Ventricular Failure. Ciruclation , 2017;136:314-326. https://www.ahajournals.org/doi/10.1161/CIRCULATIONAHA.116.025290

12. Hill JD, O’Brien TG, Murray JJ, Dontigny L, Bramson ML, Osborn JJ, et al. Prolonged extracorporeal oxygenation for acute post-traumatic respiratory failure (shock-lung syndrome). Use of the Bramson membrane lung. N Engl J Med. 1972;286:629-34.

13. Protti A, L'Acqua C, Panigada M. The delicate balance between pro-(risk of thrombosis) and anti-(risk of bleeding) coagulation during extracorporeal membrane oxygenation. Ann Transl Med . 2016;4(7):139. https://www.ncbi.nlm.nih.gov/pmc/articles/PMC4842390/\#_sec1title 